\title{
Interhemispheric, Translamina Terminalis Approach for the Resection of Suprasellar Cavernous Malformation
}

\author{
Georgios A. Zenonos ${ }^{1}$ Paul A. Gardner ${ }^{1}$ \\ ${ }^{1}$ Department of Neurosurgery, University of Pittsburgh Medical \\ Center, Pittsburgh, Pennsylvania, United States \\ Address for correspondence Paul A. Gardner, MD, Department of \\ Neurosurgery, University of Pittsburgh Medical Center, 200 Lothrop \\ Street, Suite B400, Pittsburgh, PA 15213, United States \\ J Neurol Surg B 2018;79(suppl S3):S278. \\ (e-mail: gardpa@upmc.edu).
}

\begin{abstract}
Keywords

- Cavernous Malformation

- third ventricular tumor

- translamina terminalis

- ventricular approaches

Objectives The current video presents the nuances of an interhemispheric, translamina terminalis approach for the resection of suprasellar cavernous malformation. Design The video analyzes the presentation, preoperative workup and imaging, surgical steps and technical nuances of the surgery, the clinical outcome, and follow-up imaging.

Setting The patient was treated by a skull base team at a teaching academic institution.

Participants The case refers to a 64-year-old female who presented with vision loss and confusion, and was found to have a suprasellar mass, with imaging characteristics consistent with a cavernous malformation of the third ventricle.

Main Outcome Measures The main outcome measures consist of the reversal of the patient symptoms (vision loss and confusion), the recurrence-free survival based on imaging, as well as the absence of any complications.

Results The patient's mental status improved slightly after surgery. There was no evidence of recurrence.

Conclusions The interhemispheric, translamina terminalis approach is safe and effective for the resection of suprasellar cavernous malformations.

The link to the video can be found at: https://youtu.be/z6RSAM_GnBA.
\end{abstract}

Conflict of Interest

None.

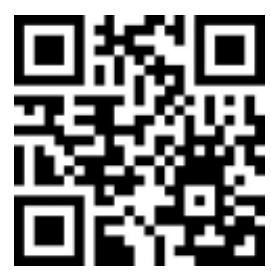

received

October 15, 2017

accepted

December 14, 2017

published online

March 7, 2018 www.thieme.com/skullbasevideos

www.thieme.com/jnlsbvideos

DOI https://doi.org/

10.1055/s-0038-1624588.

ISSN 2193-6331. (c) 2018 Georg Thieme Verlag KG
Stuttgart · New York

License terms

(c) $\odot \ominus$ 